\title{
REPRESENTAÇÕES DISCURSIVAS DA ESCOLA DEMOCRÁTICA DO DF NA MÍDIA JORNALÍSTICA
}

\author{
Thaís Lôbo JUNQUEIRA* \\ Francisca Cordelia Oliveira da SILVA**
}

- RESUMO: Neste artigo, tratamos da accountability horizontal, da accountability societal vertical, da representação e da intertextualidade a fim de analisar as representações discursivas da escola democrática, da qualidade da democracia (DIAMOND; MORLINO, 2005; O'DONNEL, 1998) e da violência (MINAYO, 2006, 2009) que reproduzem relações de dominação e de exploração (FAIRCLOUGH, 2003). Esse estudo demonstra como os efeitos potenciais de sentido que a mídia jornalística transmite, no gênero reportagem, legitimam relações sociais hegemônicas. A análise linguística dos textos verbais, não verbais e multimodais da reportagem do portal de notícias Metrópoles sobre escolas públicas do Distrito Federal focou a seleção lexical de textos verbais, o enfoque multimodal e as metáforas utilizadas com base na Análise de Discurso Crítica (ADC) (FAIRCLOUGH, 2001, 2003, 2006) e na Teoria da Semiótica Social da Multimodalidade (TSSM) (KRESS; VAN LEEUWEN, 2001, 2006 [1996]; KRESS, 2010). Nesta pesquisa, evidenciou-se que o jornalista legitimou relações sociais hegemônicas, apesar de demonstrar alto comprometimento com a identidade social criada para o Governo do Distrito Federal por meio das metáforas que utilizou e da seleção lexical que fez dos relatos dessas autoridades.

- PALAVRAS-CHAVE: Análise de discurso crítica. Representações discursivas. Teoria da semiótica social da multimodalidade. Violência escolar.

\section{Nosso mote...}

O discurso hegemônico da mídia é tema relevante para a Análise de Discurso Crítica (ADC) pela forma como os textos midiáticos institucionalizam uma visão e uma avaliação da realidade social (ideologia) e como preservam os poderes (hegemonia) de indivíduos, grupos e setores sociais, subordinando-lhes seus saberes no âmbito da comunicação e reproduzindo relações de dominação e de exploração.

\footnotetext{
* Universidade de Brasília (UnB), Instituto de Letras, Campus Universitário Darcy Ribeiro, Brasília, Distrito Federal, Brasil. thaisjunqueira.prof@gmail.com. ORCID: 0000-0001-9224-0674.

** Universidade de Brasília (UnB), Instituto de Letras, Campus Universitário Darcy Ribeiro, Departamento de Linguística, Português e Línguas Clássicas, Brasília, Distrito Federal, Brasil. cordelia.prof@gmail.com. ORCID: 0000-0001-7957-520X.
} 
Neste artigo, pretendemos investigar como os efeitos potenciais de sentido do texto verbal, não verbal e multimodal, no gênero reportagem, representam discursivamente a escola democrática, a qualidade da democracia (DIAMOND; MORLINO, 2005; O'DONNEL, 1998) e a violência (MINAYO, 2006, 2009); e como se articulam para reproduzir relações de dominação e de exploração (FAIRCLOUGH, 2003) com base nas seguintes categorias: accountability horizontal, accountability societal vertical, representação e intertextualidade.

Essas relações entre significados constroem posições ideológicas, padrões de experiência e interação social por meio de escolhas baseadas na realidade que está sendo representada, na visão de mundo que é apresentada, em quais elementos de outros textos são introduzidos, em como eles são incorporados intertextualmente, em quais são as vozes do texto, em como elas são articuladas ou silenciadas, na aproximação ou no distanciamento entre essas vozes e a do jornalista, em como a escola democrática é construída, em como os participantes da imagem se aproximam de seu leitor, em quais cores da imagem e em como as imagens são combinadas visualmente na organização do texto.

Esta investigação é qualitativa, o que demanda visão ampla do processo social e, por isso, a mais apropriada para fins de análise do tipo descritivo-interpretativo, adotada para a abordagem relacional da análise linguístico-discursiva crítica, no âmbito da Teoria Social do Discurso (TSD) (FAIRCLOUGH, 2001, 2003, 2006) e, para a análise das imagens, no âmbito da Teoria da Semiótica Social da Multimodalidade (TSSM) (KRESS; VAN LEEUWEN, 2001, 2006 [1996]; KRESS, 2010). Ela é referendada por uma pesquisa de cunho bibliográfico que fundamenta a análise da construção e da representação discursiva da realidade social, as relações de poder, a constituição de identidades e a análise das imagens do texto multimodal selecionado. No tópico a seguir, apresentamos a linguagem, a mídia jornalística e a qualidade da democracia como temas da conjuntura de produção do texto jornalístico selecionado.

\section{O discurso jornalístico como prática social}

A ADC e a TSSM são ciências sociais críticas. A abordagem sociossemiótica da Linguística surgiu com base no trabalho de Hodge e Kress (1988), fundamentada pela concepção de Halliday (1978) de linguagem como semiótica social, tendo por escopo as funções sociais da linguagem. A TSSM é uma abordagem multimodal da Semiótica Social, cujos principais representantes, Kress e van Leeuwen (2001, 2006 [1996]) e Kress (2010), declaram que a leitura multimodal contribui para a compreensão dos significados dos textos uma vez que os recursos semióticos mobilizam significados e representam as relações sociais e os eventos discursivos que permeiam a sociedade. Logo, a TSSM tem por escopo efeitos potenciais de sentido produzidos nas práticas 
comunicativas por uma pessoa por meio desses recursos semióticos da comunicação e de uma tecnologia unificada.

A TSD é uma abordagem linguístico-discursiva crítica da ADC, formalizada e aperfeiçoada por Norman Fairclough (FAIRCLOUGH, 2001, 2003, 2006), com base na concepção de Halliday $(1978,1994)$ de linguagem como semiótica social, centrada nas funções sociais da linguagem. AADC tem por escopo as relações dos textos com as práticas sociais, pois estuda a prática social da linguagem que materializa historicamente no texto relações de controle, de discriminação, de dominação e de poder.

A análise de textos como prática discursiva e social denomina-se Análise de Discurso Textualmente Orientada (ADTO). Em sua concepção tridimensional do discurso, Fairclough $(1991,2001)$ contempla três dimensões para a análise discursiva crítica: texto, prática discursiva e prática social. A análise textual baseia-se na articulação entre os valores experiencial, relacional, expressivo, metafórico, conectivo e textual (FAIRCLOUGH, 1991) e organiza-se em: vocabulário, gramática, coesão e estrutura textual (FAIRCLOUGH, 2001).

No vocabulário, são analisadas as lexicalizações alternativas (são processos de significação do mundo que ocorrem diferentemente para grupos de pessoas diferentes em tempos e épocas diferentes); as relexicalizações (é a mudança de lexicalização do domínio da experiência); o sentido (potencial) das palavras (que aborda a relação entre sentido e uso); e as metáforas. Na gramática, são analisados os tipos de oração; os modos como elementos da oração são posicionados com valor informacional (informação dada); o sistema de transitividade (uso de ativa ou passiva); o apagamento do sujeito e a modalidade. A coesão aborda o valor dos conectivos para verificar a ligação entre as orações e frases, sua estrutura e (possíveis) inferências e pressuposições que esses usos determinam. Por fim, a estrutura textual analisa a coerência global do texto.

A prática discursiva envolve os processos de produção, de distribuição e de consumo textual (FAIRCLOUGH, 2001) com base na força dos enunciados, na coerência dos textos, na intertextualidade e na interdiscursividade (ordens do discurso).

A prática social envolve a ideologia e a hegemonia (FAIRCLOUGH, 2001) com base nos efeitos das relações entre poder político e ideológico sobre o discurso, conforme descrevemos no quadro abaixo. 
Quadro 1 - Análise da Prática Social

\begin{tabular}{|c|c|}
\hline \multicolumn{2}{|r|}{ PRÁTICA SOCIAL } \\
\hline Categorias & Estágio de Análise - Explanação das relações de poder \\
\hline \multirow{3}{*}{$\begin{array}{l}\text { MATRIZ SOCIAL DO } \\
\text { DISCURSO } \\
\text { (Ideologia) } \\
\text { - Hegemonia - orientações } \\
\text { da prática social. }\end{array}$} & $\begin{array}{l}\text { Societal - relações e estruturas sociais hegemônicas existentes } \\
\text { (culturais, econômicas, ideológicas, políticas etc). }\end{array}$ \\
\hline & $\begin{array}{l}\text { Institucional - relações de poder estabelecidas com a amostra } \\
\text { discursiva. }\end{array}$ \\
\hline & $\begin{array}{l}\text { Situacional - efeitos de reprodução, de reestruturação e de } \\
\text { transformação das hegemonias existentes. }\end{array}$ \\
\hline \multirow{2}{*}{$\begin{array}{l}\text { ORDENS DO DISCURSO } \\
\text { (Social) } \\
\text { - Lutas hegemônicas }\end{array}$} & $\begin{array}{l}\text { Relações das práticas discursiva e social com as ordens do } \\
\text { discurso. }\end{array}$ \\
\hline & $\begin{array}{l}\text { Efeitos de reprodução, de desafio e de transformação das } \\
\text { ordens do discurso. }\end{array}$ \\
\hline \multirow{4}{*}{$\begin{array}{l}\text { EFEITOS IDEOLÓGICOS } \\
\text { E POLÍTICOS DO } \\
\text { DISCURSO } \\
\text { (Efeitos) }\end{array}$} & $\begin{array}{l}\text { Extensão com que a análise proposta explica a amostra } \\
\text { discursiva. }\end{array}$ \\
\hline & $\begin{array}{l}\text { Sistemas de conhecimento e de crença - extensão com que a } \\
\text { análise joga luz sobre outros dados para o analista e provê uma } \\
\text { base para outras análises. }\end{array}$ \\
\hline & $\begin{array}{l}\text { Relações sociais - se a análise se baseia no que os participantes } \\
\text { fazem em uma interação. }\end{array}$ \\
\hline & Identidades sociais - reações dos participantes à análise. \\
\hline
\end{tabular}

Fonte: Fairclough (2001, p.116-130).

A análise de textos em sentido amplo, por meio da relação dialética entre prática e estruturas sociais, denomina-se Teoria Social do Discurso (TSD). Em sua abordagem relacional da análise de textos, Fairclough $(2003,2006)$ busca compreender de forma dialética as relações externas (intertextualidade, prática social, estrutura social e os três elementos de ordens do discurso - ações, representações e identificações) e internas (fonológica, lexical, gramatical e semântica) dos textos. Por um lado, os três elementos de ordens do discurso (momentos semióticos das práticas sociais) chamados de gêneros, ou modos de (inter)agir, de discursos, ou modos de representar, e de estilos, ou modos de identificar(-se) - são elementos das práticas sociais (práticas discursivas articuladas dentro de um campo social, ou ordem do discurso) que se inter-relacionam a três significados do discurso, acional, representacional e identificacional, respectivamente, e que são interdependentes das práticas sociais e entre si. 
Por outro lado, a relação entre estrutura social, os potenciais sentidos da linguagem como semiose (sistema linguístico como instituição cujas normas e os códigos orientam os agentes sociais), e eventos sociais, que são materializados em textos (orais, escritos, multimodais, sonoros etc), é intermediada pelas práticas sociais (rituais associados a determinadas instituições e organizações).

Para a realização desta pesquisa, foram adotados os enfoques relacional para a análise de textos verbais, uma vez que foi feita a análise textual e da prática discursiva da reportagem selecionada articuladas com a análise da prática social, e o enfoque multimodal para a análise da reportagem, uma vez que os pressupostos da linguagem multimodal contemplam a língua como sistema semiótico que interage com outros sistemas de forma conjunta a fim de constituir significados.

A TSSM estabelece quatro domínios da prática social em que os sentidos são realizados sem haver hierarquia entre eles (KRESS; VAN LEEUWEN, 2001). Os quatro domínios são: a) discurso - conhecimentos socialmente construídos da realidade (gênero); b) design - o meio de realizar discursos no contexto determinado pela situação de comunicação (mídia); c) produção - a articulação na forma material do produto ou do evento semiótico (modo); e d) distribuição - preservação e reprodução de produtos e eventos semióticos.

Para a análise a ser empreendida nesta pesquisa, analisamos o discurso jornalístico como prática social sob o foco do discurso e da produção à luz da TSD e da TSSM porque o produtor do texto cria novos sentidos por meio da interdiscursividade e da variação de gênero discursivo, discurso e estilo com um propósito. Assim, o nosso interesse volta-se às origens sociais, na produção e recepção dos modos semióticos.

Com relação ao gênero textual analisado, segundo Lage (2009, p. 112), reportagem "[...] é a exposição que combina interesse do assunto com o maior número possível de dados, formando um todo compreensível e abrangente". Trata-se de gênero do jornalismo informativo, acrescido de interpretação e opinião sobre um evento social ou político de interesse geral. A reportagem é assinada por um repórter que, por meio do texto expositivo e informativo, noticia esse evento a fim de informar o leitor e, por meio de textos descritivos e narrativos, descreve ações e inclui tempo, espaço e personagens.

A mídia jornalística é uma instituição que tem exercido hegemonicamente o papel de formadora da opinião pública esclarecida sem enfrentar concorrência, pois, a nosso ver, instituições científicas, educacionais, políticas, religiosas e sociais não têm desempenhado efetivamente papel de relevância social na esfera pública. O desequilíbrio entre interesses midiáticos e interesses sociais, portanto, não diz respeito às naturezas informativa e formativa do discurso jornalístico, mas à sua natureza dialógica que é muito mais explorada pelo jornalista. Segundo Fairclough (2006, p. 84),

[...] Todos esses processos dependem da difusão social dos discursos, narrativas, ideias, práticas, valores e assim por diante, com base em sua 
legitimação, no posicionamento e na mobilização pública acerca deles, e na geração de consenso, ou pelo menos na aquiescência à mudança. ${ }^{1}$

No processo de produção, a natureza dialógica do discurso jornalístico ressalta a intersubjetividade de sua natureza democrática, de abertura ao outro, ou seja, ao sujeito para quem o jornalista escreve, que pode ser mais de um no caso dos jornais concorrentes, das fontes e dos leitores. Essa polifonia está presente na intertextualidade de seu trabalho mental por recorrer ao tecido social em busca de outros textos, desde a seleção dos fatos e dos acontecimentos, passando pela organização de suas tarefas, até a padronização de texto com base em uma gramática valorativa (FAIRCLOUGH, 2001). Desse modo, o discurso jornalístico torna-se intertextual por meio da comparação de um acontecimento com outro, da reconstituição de eventos passados e das novas leituras que faz desses eventos, legitimando-os, negando-os, acompanhando-os ou vigiando-os.

No processo de recepção, ou de distribuição/consumo, a credibilidade do discurso jornalístico depende do jornalista e do leitor. A representação da realidade por meio de histórias individuais de forma sistematizada e formal é planejada racionalmente pelo jornalista. Com base na atualidade, na memória e na antecipação de um conhecimento oral, seu texto é consumido como conhecimento científico pelo leitor porque segue as regras da escrita científica, a saber, tese apresentada na introdução, argumentos e antítese apresentados no desenvolvimento e síntese apresentada na conclusão. $\mathrm{O}$ leitor, por sua vez, espera em silêncio interpretar os fatos e os acontecimentos sozinho por meio do relato do jornalista, com base na leitura e na escuta das vozes que foram articuladas no seu texto.

A assimetria presente nos processos de produção e de recepção da reportagem selecionada nos permitiu descrever como esse contrato de leitura geralmente é quebrado pela mídia hegemônica. A legitimidade do discurso jornalístico pode ser questionada pelo leitor sempre que não for possível atribuir novos sentidos e investimentos simbólicos aos saberes do discurso informativo da reportagem com base em sua própria experiência como sujeito capaz de construir sentidos. Nesse sentido, a neutralização desses saberes no tempo e no espaço por meio do discurso oral, tornando o discurso jornalístico parte do senso comum, ou por meio do discurso científico, tornando-o conhecimento especializado, produziu efeitos potenciais de sentido no leitor em diferentes níveis de interação que o envolveram de tal forma a obrigá-lo a responder segundo regras implícitas no texto multimodal da reportagem.

Segundo Fairclough (2003), estruturas sociais e práticas sociais são mutuamente constituídas. Para ele, as práticas sociais dos membros das estruturas sociais ou de instituições sociais particulares constroem discursos situados historicamente que são realizados institucionalmente na forma de textos verbais e multimodais. Quando esses

\footnotetext{
Original: "[...] All of these processes depend upon the social dissemination of discourses, narratives, ideas, practices, values and so forth, upon their legitimization, upon the positioning and mobilization of publics in relation to them, and upon the generation of consent to or at least acquiescence with change." (FAIRCLOUGH, 2006, p.84).
} 
discursos compartilham valores culturais, sociais e simbólicos ou quando buscam o entendimento, o status de senso comum ou de consenso racional lhes é conferido, respectivamente.

Nesse sentido, a insatisfação da sociedade civil brasiliense com os serviços públicos e com o desempenho do sistema de educação pública a levou a exigir a prestação de contas do poder público por meio da reportagem do portal de notícias Metrópoles, o que pode comprometer a avaliação de sua legitimidade democrática. Essa avaliação crítica dos cidadãos diz respeito ao funcionamento não transparente da democracia no que se refere " $[. .$.$] à capacidade do sistema político de representar e incluir a enorme$ diversidade e pluralidade de interesses que constituem sociedades complexas como a brasileira." (MOISÉS, 2011, p. 27).

As duas dimensões da avaliação da qualidade da democracia (DIAMOND; MORLINO, 2005) representadas na reportagem selecionada são a:

- accountability societal vertical - ferramentas institucionais (ações legais) e não institucionais (mobilização social e denúncias) de que a sociedade civil (associações, movimentos ou mídia) dispõe para exercer controle não eleitoral. Dessa forma, ela responsabiliza o governo pelos erros e pelas falhas cometidos na utilização dos recursos públicos e luta para incluí-los na agenda pública ou para influenciar a tomada de decisões políticas que atenda às suas necessidades (O’DONNEL, 2001) e

- accountability horizontal - mecanismo de monitoramento (fiscalização exercida pelos Tribunal de Contas da União - TCU e Controladoria Geral da União - CGU), de investigação (controle exercido pelos Comissão Parlamentar de Inquérito - CPI, Ministério Público - MP e Polícia Federal - PF) e de responsabilização (correção de ações ilícitas feita pelos MP e PF) dos representantes da administração pública (atores públicos e governantes) de que dispõem de forma integrada os três poderes autônomos do Estado e os órgãos constitucionais específicos a fim de obrigá-la a responder aos cidadãos por suas decisões políticas. Na prática, o monitoramento sobre o governo é exercido por partidos políticos de oposição por meio do parlamento, apesar de haver a aplicação de normas e a emissão de avaliações pelo sistema judiciário, pelos tribunais constitucionais e pelos órgãos de auditoria, como o Banco Central, os tribunais de contas e as controladorias gerais (MOISÉS, 2011).

O contexto de produção da reportagem, portanto, situa-se na crise da escola democrática no Brasil. Como parte da prática social global, as práticas pedagógicas emancipatórias resultam da luta dentro da escola democrática para mudar as estruturas sociais injustas, pois, no Brasil, o sistema educacional reproduz relações sociais injustas de dominação e de exploração. Nessa conjuntura, a escola democrática é representada contraditoriamente como espaço de luta e de exclusão social por meio dos significados 
potenciais dos discursos da qualidade da democracia e da violência escolar salientados na reportagem.

A seguir, apresentamos os temas da conjuntura de produção do texto jornalístico selecionado, a construção do discurso jornalístico no gênero reportagem e sua articulação com algumas tipologias da violência a fim de representar a escola democrática.

\section{Os discursos da escola democrática e da violência na reportagem}

O portal Metrópoles foi lançado em 8 de agosto de 2016. Com sede em Brasília, é de propriedade do ex-senador e ex-deputado distrital, o empresário Luiz Estevão de Oliveira Neto, que financia o veículo sem participação editorial. A maior parte dos jornalistas veio da extinta Veja Brasília e do jornal Correio Braziliense. Trata-se de um portal de notícias de acesso gratuito, que representa interesses hegemônicos de direita, voltado para a cobertura da política e da sociedade na capital e nas regiões administrativas do Distrito Federal (DF), em variados aspectos, com forte ênfase na prestação de serviços. Os principais temas abordados no portal, atualizados diariamente, são educação, economia, entretenimento, esportes, gastronomia, ciência e tecnologia, política e determinados assuntos internacionais.

A reportagem documental "Relatório da Câmara Legislativa reprova escolas públicas do DF", assinada pelo jornalista João Gabriel Amador para o Caderno Distrito Federal/ Educação, foi publicada em 24 de março de 2016. Um dos modos de representação que foram mobilizados nessa reportagem de forma mais saliente é a intertextualidade (FAIRCLOUGH, 2003). A polifonia do discurso jornalístico representa discursivamente a educação pública do DF de forma irônica. Nesta pesquisa, identificamos essas vozes com o objetivo de analisar seu papel na construção desta representação.

A intertextualidade na reportagem salientou a voz explícita do deputado distrital, Reginaldo Veras, em articulação com outras vozes, a do jornalista do portal, João Gabriel Amador, a da diretora da Escola Classe 415 de Samambaia, Vera Leude da Silva, e a do diretor da Escola Classe Vila Areal, Jorge Luiz de Oliveira. A voz do Governo do DF (GDF) foi silenciada ao longo da reportagem, tendo sido citada apenas uma nota da Secretaria de Estado de Educação do DF (SEDF).

As tecnologias digitais do portal Metrópoles produzem novas composições textuais, adicionando elementos imagéticos, visuais, orais e gestuais ao novo formato de texto, tornando-o multimodal ou multissemiótico. O posicionamento desses elementos no texto pode desencadear o processo de reflexão sobre sua ironia por meio da conjuntura de produção. As desigualdades socioeconômicas são salientadas por esses elementos que fazem parte da estrutura narrativa do texto visual, evidenciando que a participação democrática paritária da sociedade civil nos espaços públicos e sua interlocução com o Estado não acontece no DF. Nesse sentido, o monitoramento sobre o governo é exercido pelo parlamento (accountability horizontal), apesar de o Tribunal de Contas do Distrito Federal - TCDF (accountability horizontal), de o Ministério Público do Distrito 
Federal e Territórios - MPDFT (accountability horizontal), de o Corpo de Bombeiros (accountability horizontal) e de a comunidade escolar (accountability societal vertical) já terem se manifestado anteriormente, de acordo com outras reportagens que são referidas no portal por meio de links.

A crise da escola democrática envolve um processo dialético: a escola sustenta o discurso do respeito à igualdade, mas reproduz e naturaliza efeitos das desigualdades sociais na distribuição da renda e dos serviços públicos. Processos sociais mais amplos articulam-se às desigualdades educacionais, como mercado de trabalho, estrutura social, a dinâmica do mercado imobiliário, da produção de moradias e as políticas estatais (TORRES, 2003), tornando a escola espaço de produção e de reprodução de relações de exclusão. Esse é o caso, por exemplo, da precariedade da infraestrutura das escolas públicas em nível elementar (água, energia, esgoto, banheiro e cozinha), o que, muitas vezes, interrompe o seu funcionamento.

Os dois tipos de manifestações que provocam sérias consequências para a vida pessoal e social (MINAYO, 2006, 2009) representados na reportagem selecionada são a:

- violência estrutural - diferentes formas de manutenção das desigualdades sociais, culturais, de gênero, etárias e étnicas por meio da submissão e da exploração de umas pessoas por outras. No caso da educação, ocorre a segregação socioespacial, e

- violência institucional - regras, normas de funcionamento e relações burocráticas e políticas das instituições que reproduzem estruturas sociais injustas. No caso da educação, um exemplo é a má qualidade do ensino.

Trata-se, na verdade, de um problema parcialmente discursivo, que dissimula questões sociais graves, como as violências estrutural e institucional, quando naturaliza discursos sobre a segregação socioespacial no DF e no Brasil, cujo IDH-D (coeficiente de desigualdade humana) é de 25,6\%, abaixo da média da América Latina, 23,2\% (PNUD, [2015]). Nesse sentido, a avaliação crítica dos cidadãos a respeito do funcionamento não transparente da democracia, evidenciado por meio dessas manifestações no ambiente escolar, compromete a consistência, a eficácia e a qualidade da democracia e da sociedade civil brasileira.

A seguir, apresentamos a prática discursiva articulada com o design do gênero reportagem documental com base nos recursos semióticos mais salientes do meio utilizado para realizar os discursos no contexto determinado pela situação de comunicação escolhida.

\section{A análise linguístico-discursiva do texto jornalístico}

Sodré e Ferrari (1986) definem o gênero reportagem documental como um relato expositivo sobre tema polêmico ou atual, apresentado de maneira objetiva e 
acompanhado de citações a fim de complementar e de esclarecer o assunto tratado. De acordo com sua estrutura sequencial (SODRÉ; FERRARI, 1986; FAIRCLOUGH, 2001), o clímax ocorre na abertura, que informa a ideia principal da reportagem por meio dos título e subtítulo; seguido pelos elementos do lide (as respostas às perguntas: Quem? O quê? Como? Quando? Onde? Por quê?), cujo resumo da reportagem pode se estender por mais de um parágrafo, o sublide; pela elaboração, em dois parágrafos, pelo desenvolvimento da história por meio de depoimentos, de entrevistas e de informações complementares e pela conclusão, fechamento ou resultado, que indica, no último parágrafo, a ação que deve ser seguida.

Para uma leitura da reportagem documental "Relatório da Câmara Legislativa reprova escolas públicas do DF" na perspectiva sociossemiótica multimodal, foi adotada a Gramática do Design Visual (GDV) de Kress e van Leeuwen (2006 [1996]). No quadro abaixo, as categorias da GDV são descritas de acordo com o significado ao qual se relacionam.

Quadro 2 - Estrutura básica da GDV

\begin{tabular}{|l|l|}
\hline Significado representacional & - Estrutura narrativa \\
& - Estrutura conceitual \\
\hline Significado interativo & - Contato \\
& - Distância social \\
& - Perspectiva \\
& - Modalidade \\
\hline Significado composicional & - Valor da informação \\
& - Saliência \\
& - Estruturação \\
\hline
\end{tabular}

Fonte: Kress e van Leeuwwen (2006 [1996], p. 59, 74, 149, 210).

$\mathrm{Na}$ reportagem selecionada, identificamos essas categorias a fim de analisar os componentes representacionais ao tratar do conteúdo e do discurso e identificamos a intertextualidade (FAIRCLOUGH, 2003) a fim de analisar os componentes composicionais ao tratar de sua produção, que relaciona o conteúdo à composição textual. Os significados representacional e composicional são detalhados nos quadros abaixo. 


\begin{tabular}{|c|c|}
\hline & SIGNIFICADO REPRESENTACIONAL \\
\hline \multicolumn{2}{|c|}{$\begin{array}{l}\text { O significado representacional apresenta o desenvolvimento de ações e de eventos, } \\
\text { processos de mudança e disposições espaciais transitórias. Ele constitui-se de: }\end{array}$} \\
\hline $\begin{array}{l}\text { ESTRUTURA } \\
\text { NARRATIVA }\end{array}$ & $\begin{array}{l}\text { Representada por vetores (traço indicador de direção) que indicam } \\
\text { a realização de uma ação ou de um evento durante o processo de } \\
\text { interação entre dois participantes. }\end{array}$ \\
\hline \multicolumn{2}{|r|}{ No processo narrativo, o vetor nos permite distinguir a: } \\
\hline Ação & $\begin{array}{l}\text { O ator é participante da ação da qual o vetor emana (o vetor parte } \\
\text { do ator). }\end{array}$ \\
\hline Reação & $\begin{array}{l}\text { O participante dirige o olhar do qual o vetor emana (o olhar de um } \\
\text { participante reflete em outro). }\end{array}$ \\
\hline \multicolumn{2}{|r|}{ A reação pode ser: } \\
\hline Verbal & $\begin{array}{l}\text { O participante conecta-se ao enunciado por meio do vetor (a fala } \\
\text { do participante, ou dizente, é representada por meio de um balão } \\
\text { de fala). }\end{array}$ \\
\hline Mental & $\begin{array}{l}\text { O experienciador conecta-se ao fenômeno, ou seja, ao seu } \\
\text { pensamento, por meio do vetor (o pensamento do experienciador, } \\
\text { ou participante, é representado por meio de balão de pensamento). }\end{array}$ \\
\hline $\begin{array}{l}\text { ESTRUTURA } \\
\text { CONCEITUAL }\end{array}$ & $\begin{array}{l}\text { Classifica os participantes envolvidos, representando-os conforme } \\
\text { suas particularidades. }\end{array}$ \\
\hline \multicolumn{2}{|c|}{$\begin{array}{l}\text { A estrutura conceitual representa a essência atemporal e estável dos participantes por } \\
\text { meio da classe, da estrutura ou do significado. Ela compreende os seguintes processos: }\end{array}$} \\
\hline Classificatório & $\begin{array}{l}\text { As taxonomias relacionam os participantes entre si. Assim, o } \\
\text { papel de um grupo de participantes estará subordinado ao de outro } \\
\text { participante, o superordenado. }\end{array}$ \\
\hline Analítico & $\begin{array}{l}\text { Dois tipos de participantes em termos da estrutura conceitual "parte- } \\
\text { todo" existem: o que se relaciona ao "todo" é o portador e o que } \\
\text { diz respeito às "partes" do portador, ou seja, aos seus atributos } \\
\text { possessivos. }\end{array}$ \\
\hline \multicolumn{2}{|r|}{ Os processos analíticos subdividem-se em: } \\
\hline Estruturado & Apresenta o portador (o todo). \\
\hline Desestruturado & Apresenta um ou mais atributos possessivos do portador (as partes). \\
\hline Simbólico & O que "significa" o participante da imagem ou o que ele "é". \\
\hline \multicolumn{2}{|r|}{ Os processos analíticos simbólicos subdividem-se em: } \\
\hline Portador & $\begin{array}{l}\text { O sentido ou identidade que ele estabelece na relação com o outro } \\
\text { participante. }\end{array}$ \\
\hline Atributo simbólico & O sentido ou identidade é representado por outro participante. \\
\hline
\end{tabular}

Fonte: Kress e van Leeuwwen (2006 [1996], p. 45-113). 


\section{Quadro 4 - Significado Composicional}

\section{SIGNIFICADO COMPOSICIONAL}

No sentido composicional do texto, os elementos visuais da imagem são organizados e/ou combinados para que ela faça sentido, integrando elementos representacionais e interativos em uma composição textual. Ele é formado pelos seguintes elementos:

\section{VALOR DA \\ INFORMAÇÃO (VI)}

ESTRUTURAÇÃO

(E) (ou Moldura)
A informação é considerada uma estrutura ideológica com base no ponto de vista particular do participante representado e do leitor de imagens, de acordo com a forma como estão posicionados na imagem, "esquerda-direita", "topo-base" ou "centro-margem".

A maior ou menor ênfase que certos elementos recebem em relação a outros na imagem atrai ou não a atenção do leitor de imagens em diferentes níveis: plano de fundo ou primeiro plano, tamanho, contrastes de tons ou de cores, diferenças de nitidez etc.

Os elementos do texto fortemente posicionados no enquadramento visual revelam conexão entre os elementos da composição se estiverem visualmente unidos por meio de vetores, das continuidades ou similaridades de cor e de formato visual e da ausência de enquadramento da imagem.

Os elementos do texto fracamente posicionados no enquadramento visual revelam desconexão entre os elementos da composição se estiverem visualmente separados uns dos outros por meio de linhas, de aspectos do enquadramento da imagem, de espaços vazios entre os elementos e de descontinuidades de cor e de formato visual.

Assim, o universo do discurso compreende o conteúdo representacional do texto em análise.

Fonte: Kress e van Leeuwwen (2006 [1996], p.175-214).

A GDV orienta a análise multimodal dos significados identificados no corpus por meio das seguintes categorias de análise: valor informacional (topo e base, centro e margem, dado e novo), saliência e enquadre (conexão), em diálogo com a visão de mundo, com as relações sociais, com a coerência interna e externa (contexto) do texto, ou seja, da reportagem analisada.

O espaço visual da reportagem selecionada pode ser dimensionado como ilustra a figura abaixo, que define as dimensões do espaço visual. 
Figura 1 - Dimensões do espaço visual

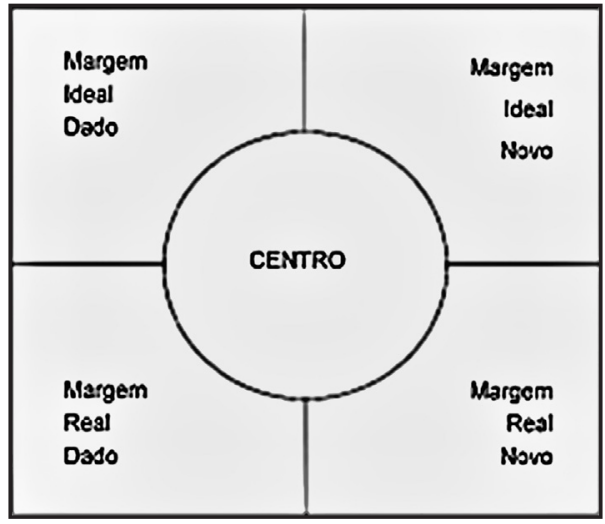

Fonte: Kress e van Leeuwwen (2006 [1996], p.197).

O dado é o elemento situado à esquerda e o novo, à direita. Eles não se confundem e são diferenciados pela composição polarizada do espaço visual. O ideal é o elemento situado no topo e o real, no fundo. Eles também não se confundem e são diferenciados pela composição centralizada do espaço visual. No tópico a seguir, apresentamos alguns resultados da análise da reportagem selecionada.

\section{Análise da reportagem}

Antes da análise, apresentamos a parte verbal do texto:

\section{Relatório da Câmara Legislativa reprova escolas públicas do DF \\ Salas sem ventilação, inexistência de quadras poliesportivas, falhas elétricas e falta de água são alguns dos problemas identificados. \\ Presidente da Comissão de Educação, Saúde e Cultura afirma que, em alguns casos, o melhor seria demolir unidades de ensino}

O GDF não tem feito a lição de casa, embora não faltem deveres a serem concluídos. Os sucessivos relatos na imprensa sobre a má condição das escolas públicas locais, as reclamações de pais e alunos, os alertas de professores e até mesmo levantamentos de órgãos oficiais - como relatório do Tribunal de Contas do DF (TCDF) — não foram suficientes para melhorar as condições das instituições. Agora, um novo documento reforça os graves problemas que fazem parte do cotidiano de quem passa o dia entre lousas, livros, cadernos e carteiras. Segundo o presidente da Comissão de Educação, Saúde e Cultura da Câmara Legislativa, deputado Reginaldo Veras (PDT), em alguns casos, a situação é tão crítica que os edifícios deveriam ser demolidos. 
O parlamentar visitou mais de 50 colégios nas 14 regionais de ensino e elaborou um relatório com as observações feitas nos locais. Na sessão de terça-feira (22/3), Veras chegou a dizer que alguns deveriam ser implodidos antes que causassem danos mais graves aos alunos. Entre as unidades citadas, estão a Escola Classe 415 de Samambaia (foto principal) e a Escola Classe Vila Areal. A reportagem do Metrópoles esteve nos dois endereços e conferiu de perto o descaso do Estado com a infraestrutura dessas instituições.

Na Escola Classe 415 de Samambaia, cerca de 580 alunos do ensino fundamental, até $5^{\circ}$ ano, têm de enfrentar desafios diários para aprender. A começar pelo calor nas salas de aula. "O colégio foi construído há 24 anos de forma provisória. Os prédios foram feitos com pé-direito baixo e com placas de concreto, o que deixa os ambientes muito quentes", explica a diretora da unidade, Vera Leude da Silva. Ela conta também que, por ter o sistema elétrico antigo, não há como instalar ar-condicionado, e até mesmo os ventiladores têm problemas.

$\mathrm{Na}$ época das chuvas, a situação é ainda pior. Rachaduras no teto transformam salas em cachoeiras e professores tem de levar os alunos para outro local. "A água ainda escorre pelas paredes e alcança as tomadas, gerando riscos de curto-circuito", comenta Vera.

\section{Mangueiras de incêndio}

No lado de fora, mais obstáculos. As mangueiras de incêndio estão inutilizáveis e a escola foi notificada pelos bombeiros. Na suposta área de lazer, o mato e cupinzeiros tomam conta do espaço. Até caco de vidro fica escondido em meio a vegetação. Não há quadra coberta, e o parquinho precisa de manutenção.

As condições críticas fizeram a diretora recorrer ao Ministério Público. “Aguardamos um mandado para que a Secretaria de Educação seja obrigada a tomar uma atitude”, afirma.

\section{Caixa d'água quebrada}

No Areal, as dificuldades são semelhantes. O prédio também foi construído em caráter provisório, em 1971, com telhas de zinco e paredes baixas, que também contribuem para o calor. O ambiente quente é ainda mais prejudicial pelas constantes faltas de água. "Nossa caixa d'água está quebrada desde 2012. Só neste ano, mandei três pedidos para a secretaria enviar alguém para resolver a situação", relata o diretor Jorge Luiz de Oliveira. Sem o equipamento, a escola fica vulnerável às faltas de água da região. "Algumas vezes temos de liberar os estudantes", completa Oliveira.

As chuvas também atrapalham. Sem sistema de escoamento adequado, a lama escorre para a quadra coberta, tirando dos alunos uma das poucas melhorias conquistadas.

Em nota, a Secretaria de Educação informou que as duas escolas citadas constam no Plano de Obras 2015-2018 da pasta. "Ressalta-se a necessidade de providenciar a gestão dos recursos. Após a garantia de orçamento, poderá se falar em previsão de prazos”. 


\section{Além das escolas}

Para o deputado Reginaldo Veras, as dificuldades estruturais são consequências de problemas administrativos da educação. O relatório aponta a necessidade de construção de novas escolas para atender a demanda por vagas. "Um exemplo disso é a região do Paranoá, onde a carência é de cerca de 7,5 mil vagas", destacou.

Outra questão é o repasse de verbas para os colégios. Segundo Veras, o sistema educacional sofre com a falta de investimentos. "É preciso que o governo determine prioridades. E a educação tem que ser uma delas". Para ele, mesmo quando há dinheiro, faltam pessoas. "Já tentei encaminhar parte da emenda parlamentar para o setor, mas a secretaria tem déficit de profissionais, como engenheiros e arquitetos, o que dificulta o processo de reforma de colégios", aponta.

Por fim, o deputado sugeriu a ampliação do Programa de Descentralização Administrativa e Financeira (PDAF), que prevê o repasse direto de verbas para diretores de escolas, dando autonomia para pequenos reparos e reformas. (AMADOR, J. G., 24 mar. 2016).

A reportagem, por meio de uma estrutura conceitual ambígua, foi construída com base em um ângulo pessoal, com o jornalista manifestando sua opinião (em 1) já no início do texto.

(1) $[\ldots]$ A reportagem do Metrópoles [...] conferiu de perto o descaso do Estado com a infraestrutura dessas instituições.

A seleção lexical de "descaso do Estado" (em 1) revela o comprometimento do jornalista com a identidade social criada para o GDF com base nos relatos citados. Por um lado, o jornalista relatou o descaso do Estado com a infraestrutura da Escola Classe 415 de Samambaia e da Escola Classe Vila Areal por meio dos diferentes modos de representação mobilizados no texto. Por outro, ele naturalizou discursos sobre a segregação socioespacial da população pobre (violência institucional) e os efeitos das desigualdades sociais na distribuição da renda e dos serviços públicos (violência estrutural).

Por meio de uma estrutura narrativa bem marcada, os discursos direto e indireto mesclaram-se para construir significados e para apresentar outras vozes no texto, geralmente de especialistas, isentando o jornalista de analisar os fatos e dando credibilidade ao que é dito. A fim de prender a atenção do público, fatos e informações foram resumidos nos primeiro (o lide) e segundo (o sublide) parágrafos e relatados em ordem decrescente de importância no decorrer do corpo da reportagem. A estrutura da abertura da reportagem do portal Metrópoles é ilustrada na figura abaixo. 
Figura 2 - Excerto da abertura da seção Distrito Federal/ Educação do portal Metrópoles, 24 Mar. 2016

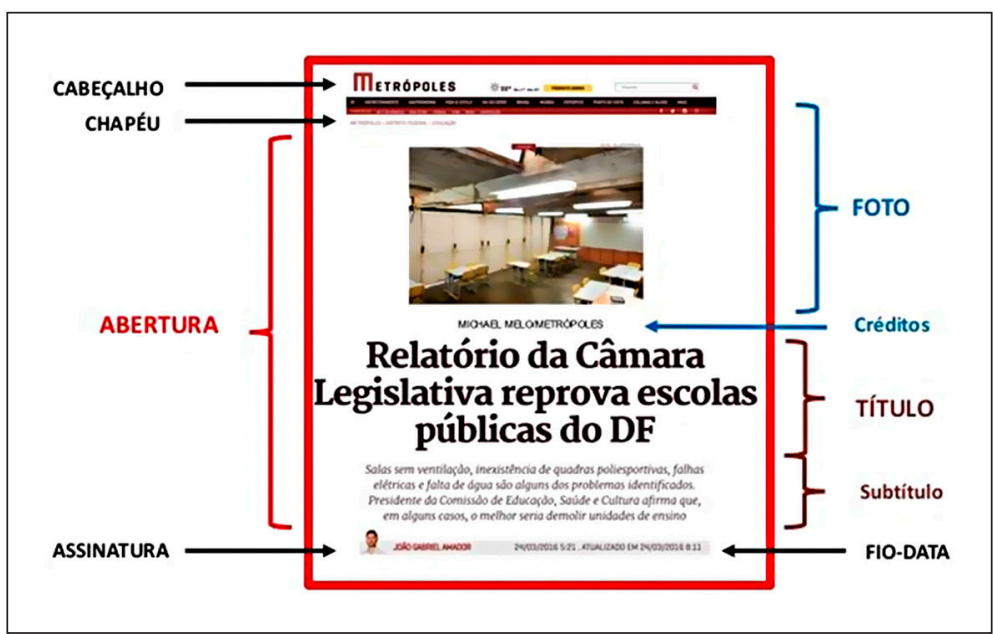

Fonte: Amador (24 mar. 2016).

Na abertura, a fotografia de uma sala de aula da Escola Classe 415 de Samambaia, referida no sublide como "(foto principal)", sem estudantes nem professores, serviu de clímax. O título, "Relatório da Câmara Legislativa reprova escolas públicas do DF", chamou a atenção para o tema polêmico que será abordado, o relatório sobre as escolas públicas, situando-o no espaço, DF. Ao posicionar a foto antes do título e ao selecionar o verbo "reprova", o jornalista produz um efeito potencial de sentido que pode levar o leitor da imagem a pressupor que a escola que aparece na foto não está mais em funcionamento porque foi reprovada na avaliação da Câmara Legislativa e que essa reprovação foi registrada em um relatório.

(2) [...] Salas sem ventilação, inexistência de quadras poliesportivas, falhas elétricas e falta de água são alguns dos problemas identificados.

(3) Presidente da Comissão de Educação, Saúde e Cultura da Câmara Legislativa afirma que, em alguns casos, o melhor seria demolir unidades de ensino.

O subtítulo informou o motivo da reprovação (como se pode ver no excerto 2) e deu exemplos (excerto 3) antes de fechar com a citação de uma autoridade política e de informar sua opinião sobre esse assunto. Ao citar o Presidente da CESC (em 3) o jornalista apresenta uma autoridade do Poder Legislativo e, assim, busca credibilidade para sua declaração.

A estrutura da primeira parte do corpo da reportagem do portal Metrópoles é ilustrada na figura abaixo. 
Figura 3 - Excerto do corpo de texto da seção Distrito Federal/

Educação do portal Metrópoles, 24 Mar. 2016

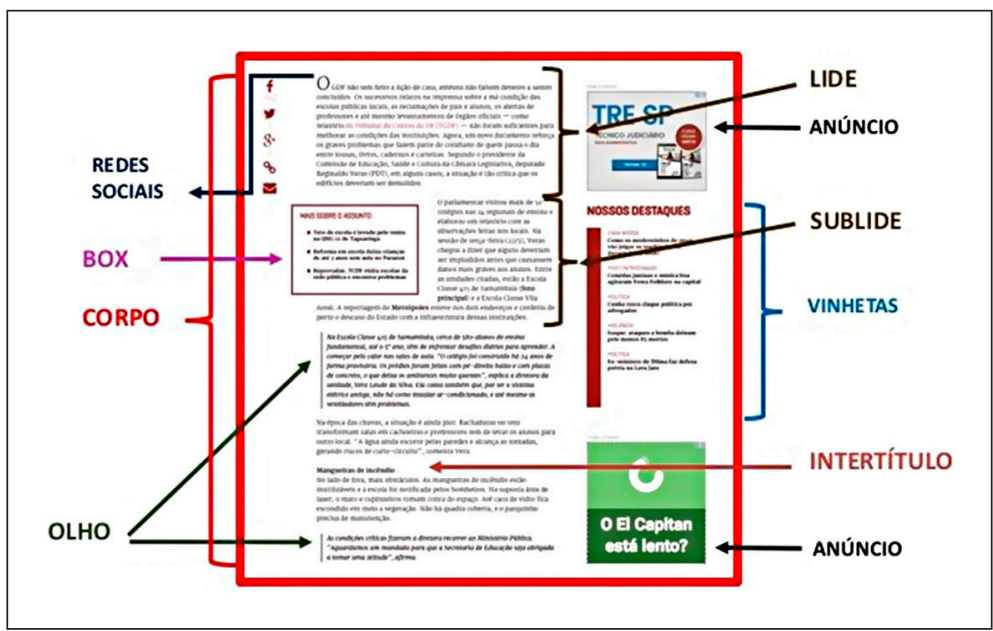

Fonte: Amador (24 mar. 2016).

No primeiro parágrafo do corpo da reportagem, o jornalista introduziu o lide, no corpo da reportagem, por meio de uma metáfora (LAKOFF; JOHNSON, 2002, p.45) (em 4) que é explicada em seguida (em 5).

(4) O GDF não tem feito a lição de casa, embora não faltem deveres a serem concluídos.

(5) Os sucessivos relatos na imprensa sobre a má condição das escolas públicas locais, as reclamações de pais e alunos, os alertas de professores e até mesmo levantamentos de órgãos oficiais - como relatório do Tribunal de Contas do DF (TCDF) [...].

Essa metáfora (em 4) revela, de forma irônica, o comprometimento do jornalista com a identidade social criada para o GDF. A justaposição dessa metáfora com a frase (em 5) produz o efeito potencial de sentido que pode levar o leitor a comparar o comportamento do GDF com o dos estudantes da rede pública de ensino em relação ao cumprimento dos deveres escolares e que o GDF deve prestar contas à sociedade civil (accountability societal vertical) dos serviços públicos negligenciados (violência institucional).

O jornalista também explicou como a ação do Legislativo aconteceu (em 6). 
(6) [...] Agora, um novo documento reforça os graves problemas que fazem parte do cotidiano de quem passa o dia entre lousas, livros, cadernos e carteiras.

(7) Segundo o presidente da Comissão de Educação, Saúde e Cultura da Câmara Legislativa, deputado Reginaldo Veras (PDT), [...], a situação é tão crítica que os edifícios deveriam ser demolidos [...].

A seleção lexical do advérbio "agora" (em 6) salienta a reincidência do GDF em não atender aos interesses da população e produz o efeito potencial de sentido que pode levar o leitor a pressupor que o funcionamento da democracia no DF não é transparente e que a Câmara Legislativa pode resolver esse problema.

Para fechar (em 7) o jornalista informou o nome e o partido da autoridade política mencionada anteriormente no subtítulo, mencionando-o novamente. Ao citar o nome e o partido do Presidente da CESC, o jornalista novamente representa uma autoridade do Poder Legislativo, salientando sua filiação a um partido de oposição ao GDF, o que produz um efeito potencial de sentido que pode levar o leitor a pressupor que a oposição também está monitorando o GDF (accountability horizontal) sobre essa situação.

No segundo parágrafo (em 8), o sublide, o jornalista e informou de que trata o relatório da Câmara Legislativa. O jornalista também situou o fato no tempo, 22/03/16, e explicou o motivo da declaração do parlamentar (em 9), e informou que a equipe de reportagem do Metrópoles esteve em duas escolas para investigar o fato (em 1).

(8) [...] O parlamentar visitou mais de $\underline{50 \text { colégios nas } 14 \text { regionais de ensino } \mathrm{e}}$ elaborou um relatório com as observações feitas nos locais.

(9) Na sessão de terça-feira (22/3), Veras chegou a dizer que alguns deveriam ser implodidos antes que causassem danos mais graves aos alunos.

Após o lide, aparecem dois olhos ${ }^{2}$, nos terceiro e sexto parágrafos, com citações da diretora da Escola Classe 415 de Samambaia, Vera Leude da Silva (em 10-12), sobre a situação das salas de aula e sobre o mandado do MPDFT. A seleção lexical dos adjuntos adverbiais "de forma provisória" e "há 24 anos" (em 10), produz o efeito potencial de sentido que pode levar o leitor a pressupor uma situação de abandono dessa escola pública pelo poder público que dura bastante tempo.

O "olho" de uma reportagem de jornal é uma frase relevante e interessante da matéria apresentada em negrito. A fonte em tamanho maior que a da reportagem permite a quem lê o olho ter uma noção do assunto antes mesmo de terminar a leitura da reportagem. 
(10) [...] "O colégio foi construído há 24 anos de forma provisória" [...], explica a diretora da unidade, Vera Leude da Silva.

(11) $[\ldots]$ No período das chuvas [...]. Rachaduras no teto transformam salas em cachoeiras e professores têm de levar os alunos para outro local.

(12) "A água ainda escorre pelas paredes e alcança as tomadas, gerando riscos de curto-circuito", comenta Vera.

No quarto parágrafo, a metáfora "salas em cachoeiras" (em 11) é salientada pelo jornalista que dedica todo o parágrafo para descrever a precariedade das salas de aula no período de chuvas e para informar o risco de curto-circuito (em 12).

A disposição dos recursos semióticos da página à esquerda e à direita representa informações anteriores (dado) e novas (novo), respectivamente. À esquerda da página (dado), identificamos alguns botões para navegação nas redes sociais em que o portal Metrópoles foi registrado e um box com três links para outras reportagens sobre a precariedade das instalações físicas das escolas públicas do DF e sobre o relatório do TCDF. À direita da página (novo), são informadas algumas vinhetas de novas notícias, bem como dois anúncios.

No quinto parágrafo, o intertítulo "mangueira de incêndio" representa uma quebra na continuidade do que foi dito anteriormente a fim de facilitar a leitura. Nesse parágrafo, as vozes da diretora Vera e do jornalista mesclaram-se, como se fossem uma única voz, pois ele só se referiu a ela no segundo olho. Nesse trecho da reportagem, a diretora relatou a situação da parte externa da escola (em 13-16).

(13) [...] As mangueiras de incêndio estão inutilizáveis e a escola foi notificada pelos bombeiros.

(14) Na suposta área de lazer, o mato e cupinzeiros tomam conta do espaço.

(15) Até caco de vidro fica escondido em meio a vegetação.

(16) [...] As condições críticas fizeram a diretora recorrer ao Ministério Público. "Aguardamos um mandado para que a Secretaria de Educação seja obrigada a tomar uma atitude", afirma.

A seleção lexical do adjetivo "suposta" (em 14) e da preposição "até" (em 15) produz o efeito potencial de sentido que pode levar o leitor a pressupor que essa situação de abandono dura bastante tempo em um espaço destinado à área de lazer. Em seguida, a diretora relatou que acionou o MPDFT (em 16). A seleção lexical de "as condições críticas", "Ministério Público", "mandado", "Secretaria de Educação" e "obrigada a tomar uma atitude" produz o efeito potencial de sentido que pode levar o leitor a pressupor que há tensão entre a comunidade escolar e o poder público que dura algum tempo e que, por isso, o MPDFT monitora o GDF (accountability horizontal) sobre essa situação. 
$\mathrm{O}$ distanciamento do jornalista em relação à diretora, nesse momento, pode ser observado nas fotos da abertura da reportagem e do slideshow que sucedem o intertítulo. As fotos foram sequenciadas de acordo com a narrativa da diretora Vera, servindo como testemunho visual do que ela narra, o que torna a reportagem documental. A estrutura da segunda parte do corpo da reportagem do portal Metrópoles é ilustrada na figura abaixo.

Figura 4 - Excerto do corpo de texto da seção Distrito Federal/

Educação do portal Metrópoles, 24 Mar. 2016

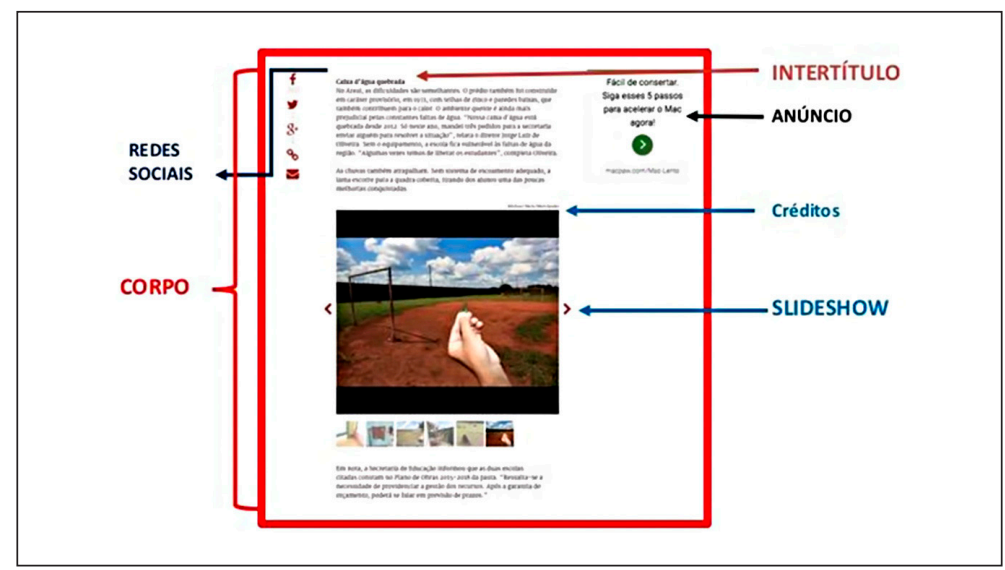

Fonte: Amador (24 mar. 2016).

No sétimo parágrafo, o intertítulo "Caixa d'água quebrada” representa uma mudança de assunto a fim de informar a situação de outra escola, a Escola Classe Vila Areal (em 17-21), segundo o relato feito pelo diretor. O jornalista fez uso novamente da citação de um sujeito ligado ao contexto para representar uma autoridade do Poder Executivo (em 20) e, assim, obter credibilidade para sua declaração.

(17) No Areal, as dificuldades são semelhantes [...].

(18) O prédio também foi construído em caráter provisório, em 1971, com telhas de zinco e paredes baixas, que também contribuem para o calor.

(19) [...] Nossa caixa d'água está quebrada desde 2012.

(20) Só neste ano, mandei três pedidos para a secretaria enviar alguém para resolver a situação", relata o diretor Jorge Luiz de Oliveira [...].

(21) Sem equipamento, a escola fica vulnerável às faltas de água da região.

Por um lado, a seleção lexical de "as dificuldades são semelhantes” (em 17), "em caráter provisório", “em 1971" (em 18), "desde 2012” (em 19) e "três pedidos" (em 20) produz o efeito potencial de sentido que pode levar o leitor a comparar a situação 
desta escola com a da Escola Classe 415 de Samambaia, pois ambas funcionam em prédios provisórios, e a pressupor que a situação de abandono das escolas públicas pelo poder público dura bastante tempo. Por outro, a posterior seleção lexical de "faltas de água na região" (em 21) e "o calor" (em 18) produz um efeito potencial de sentido que pode levar o leitor a pressupor que o sistema hídrico da cidade do Areal não é eficiente.

No oitavo parágrafo, as vozes do diretor e do jornalista mesclaram-se (em 22) como se fossem uma única voz, pois ele não se referiu mais ao diretor. A seleção lexical de "sem um sistema de escoamento adequado", "a lama", "a quadra coberta" e "uma das poucas melhorias conquistadas" produz o efeito potencial de sentido que pode levar o leitor a pressupor que a luta da comunidade escolar é necessária para melhorar as instalações da escola e a vida da comunidade em que se insere (accountability societal vertical).

(22) [...] Sem um sistema de escoamento adequado, a lama escorre para a quadra coberta, tirando dos alunos uma das poucas melhorias conquistadas.

No nono parágrafo, o jornalista citou uma nota da SEDF (em 23). A seleção lexical de "Plano de Obras 2015-2018", "necessidade de providenciar", "garantia de orçamento", "poderá" e "previsão de prazos" produz o efeito potencial de sentido que pode levar o leitor a pressupor que o governo não dispõe de recursos necessários para resolver os problemas apontados pelas duas escolas e que não houve o repasse de verba pública para ele.

(23) $[. .$.$] as duas escolas citadas constam no Plano de Obras 2015-2018 da pasta.$ "Ressalta-se a necessidade de providenciar a gestão dos recursos. Após a garantia de orçamento, poderá se falar em previsão de prazos".

A estrutura do fechamento da reportagem do portal Metrópoles é ilustrada na figura abaixo. 
Figura 5 - Excerto do fechamento da seção Distrito Federal/

Educação do portal Metrópoles, 24 Mar. 2016

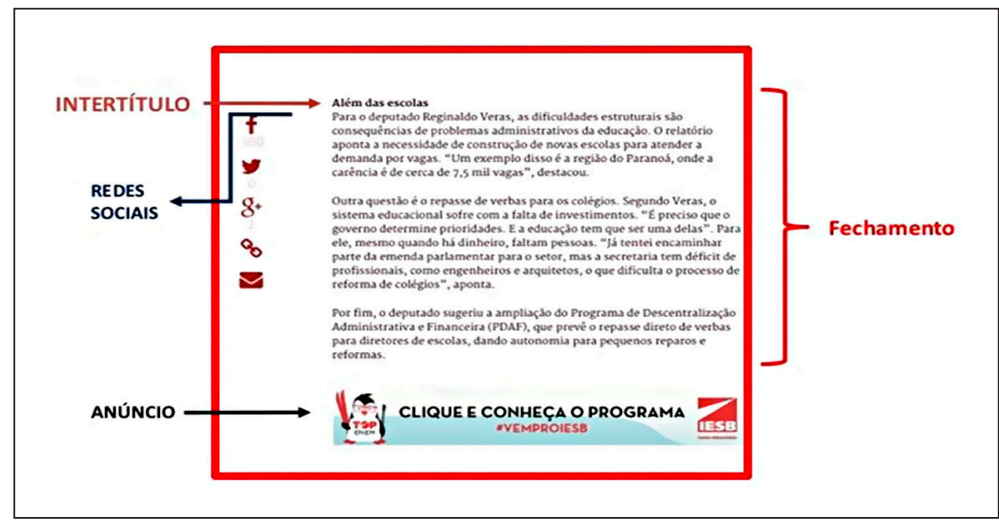

Fonte: Amador (24 mar. 2016).

No décimo parágrafo, o intertítulo "Além das escolas" representa uma mudança de assunto a fim de tratar da conclusão do relatório da Câmara legislativa. Após citar a conclusão do deputado Reginaldo Veras (em 24), o jornalista informou outra conclusão do relatório da CESC da Câmara Legislativa (em 25).

(24) [...] Para o deputado Reginaldo Veras, as dificuldades estruturais são consequências de problemas administrativos da educação.

(25) [...] O relatório aponta a necessidade de construção de novas escolas para atender a demanda por vagas.

A seleção lexical de "além das escolas", no intertítulo, "dificuldades estruturais", "problemas administrativos" (em 24), "necessidade" e "demanda" (em 25) produz o efeito potencial de sentido que pode levar o leitor a pressupor que o governo não é responsável pela precariedade da infraestrutura das escolas públicas - água, energia, esgoto, sanitário -, que, muitas vezes, interrompe o seu funcionamento, ou que há outras necessidades sociais mais urgentes para o governo atender.

O silêncio do GDF, que não foi procurado pela reportagem do portal Metrópoles, produz o efeito potencial de sentido que pode levar o leitor a pressupor que o portal não quer responsabilizá-lo pelos problemas de infraestrutura apontados pela direção das duas escolas e pelo deputado distrital; nem quer aprofundar o tema para tratar da segregação socioespacial das comunidades do Areal e de Samambaia. Por isso, o jornalista mudou de assunto para tratar da demanda por vagas na rede pública de ensino do DF e do repasse de verbas para as escolas (em 26-29). 
(26) [...] Outra questão é o repasse de verbas para os colégios.

(27) Segundo Veras, o sistema educacional sofre com a falta de investimentos.

(28) "É preciso que o governo determine prioridades $[\ldots]$ ".

(29) $[\ldots]$ "Para ele, mesmo quando há dinheiro, faltam pessoas. [...] mas a secretaria tem déficit de profissionais, como engenheiros e arquitetos, o que dificulta o processo de reforma de colégios", aponta.

A seleção lexical de "outra questão" (em 26), "falta de investimentos" (em 27), "prioridades" (em 28) e "déficit de profissionais" (em 29), produz o efeito potencial de sentido que pode levar o leitor a pressupor que não há profissionais das áreas de engenharia e de arquitetura trabalhando para o GDF (em 29). Porém, o Metrópoles não aprofundou o tema para tratar da desigualdade da distribuição da renda no Brasil, que repercute nos baixos salários dos servidores do GDF, salientando apenas o problema do repasse de verba pública às escolas públicas (em 26 e 27) sem investigar porque as escolas não a recebem.

No fechamento, o jornalista citou a sugestão do deputado Reginaldo Veras (em 30) para atender as necessidades de reparos e de reformas mais urgentes das escolas.

(30) [...] o deputado sugeriu a ampliação do Programa de Descentralização Administrativa e Financeira (PDAF) [...].

Porém, esses recursos não se destinam à construção de novas escolas (em 26 e 29) nem à demolição das escolas que foram reprovadas pelo relatório da CESC da Câmara Legislativa (em 3, 7 e 9).

Por um lado, as condições de uso dos operadores argumentativos direcionam o leitor a uma conclusão específica por meio do sentido apontado por eles. Por exemplo, a seleção lexical de "as condições críticas" (em 16), "as dificuldades são semelhantes" (em 17), "faltas de água na região" (em 21), "sem um sistema de escoamento adequado" (em 22) e "mesmo quando há dinheiro, faltam pessoas" (em 29) e as metáforas "O GDF não tem feito a lição de casa" (em 4) e "salas em cachoeira" (em 11) indicam o propósito dos falantes na elaboração de seu discurso, produzindo o efeito potencial de sentido que pode levar o leitor a entender que a má conservação das escolas públicas do DF decorre da omissão do GDF e da vulnerabilidade social do território em que se localizam.

Por outro, apesar de aspectos multimodais da reportagem salientarem a gravidade dos episódios descritos verbalmente pelos entrevistados de duas escolas públicas, o jornalista, no encerramento da reportagem não cobra nenhuma solução para o que chamou de "descaso do Estado com a infraestrutura dessas instituições" (no excerto 1). Por exemplo, o tamanho da fonte do título "Relatório da Câmara Legislativa reprova escolas públicas do DF" (Figura 2), as fotos da abertura da reportagem (Figura 2) e do 
slideshow no corpo da reportagem (Figura 4), os links de outras reportagens semelhantes no box e os dois olhos no corpo da reportagem (Figura 3) contrastam com a seleção lexical do intertítulo "além das escolas" no encerramento da reportagem (Figura 5), produzindo o efeito potencial de sentido que pode levar o leitor a entender que o jornalista, ao mudar de assunto no fechamento da reportagem, comprometeu a identidade social criada para o Governo do Distrito Federal sem cobrar dele uma solução para a infraestrutura precária das escolas que a reportagem investigou.

Em razão do que foi exposto anteriormente, o jornalista encerra a reportagem sem investigar a fundo outras causas, diferentes da econômica, das desigualdades sociais materializadas na precariedade das instalações físicas das escolas públicas e da infraestrutura urbana do DF que as autoridades entrevistadas denunciaram.

\section{Considerações finais}

A falta de transparência do sistema democrático do DF impede a participação democrática paritária da sociedade civil nos espaços públicos e sua interlocução com o Estado, como a reportagem salientou. Nesse sentido, na avaliação feita pela comunidade escolar, a democracia brasileira lhes garante liberdade para exercer o controle social e para denunciar sua realidade social a órgãos públicos (accountability horizontal), porém não lhes garante os recursos necessários para que haja igualdade social.

A mídia jornalística, no entanto, é um canal privilegiado de manifestação tanto das lutas políticas quanto do poder. Por seu engajamento na formação de consensos, a sociedade civil enxerga a mídia como ferramenta poderosa de denúncia da má utilização dos recursos públicos (accountability societal vertical), capaz de provocar mudança social. Por isso, a situação em que se encontram as escolas públicas do DF também foi denunciada pela mídia jornalística.

Vimos, por meio das estruturas conceitual e narrativa da reportagem, que as informações do jornalista reconstituíram fatos e acontecimentos narrados por meio de suas escolhas discursivas e de seu estilo particular, ilustradas com fotos e referenciadas pelos links de reportagens anteriores no portal de notícias Metrópoles. Assim, o texto veiculado na mídia eletrônica é opinativo, descritivo e analítico e destina-se ao público em geral. Essas escolhas produziram efeitos potenciais de sentido, o que pode levar o leitor a fazer pressuposições relacionadas com as redes de práticas sociais, como as que explanamos durante esta análise.

As estratégias das escolhas feitas, tais como as escolhas lexicais de caráter disfórico (negativo), o uso de metáforas e o enfoque de aspectos da multimodalidade, concorrem, como operadores argumentativos, para criar e/ou sugerir determinados efeitos de sentido que desvelam a interferência da subjetividade a permear a suposta objetividade da reportagem. Assim, em vez do jornalista resumir os fatos que investigou em duas escolas na abertura e no corpo da reportagem e se posicionar em relação a eles no fechamento da reportagem, ele opta por tratar da demanda por 
vagas escolares no Paranoá (no excerto 25) e da destinação de orçamento público diretamente para as escolas públicas (no excerto 30) no fechamento da reportagem e por não contradizer a nota da SEDF (no excerto 23) de que não há verba para reformá-las com base na declaração do deputado Veras (no excerto 29), produzindo o efeito potencial de sentido que pode levar o leitor a entender que a precariedade da infraestrutura das escolas públicas é um problema estrutural causado por problemas administrativos da educação, como foi apontado pelo Deputado Veras (no excerto 24), e não pelo descaso do Estado, como foi apontado por diretores das duas escolas (nos excertos 16 e 20).

Por meio da intertextualidade, os discursos educacionais, políticos e jornalísticos da reportagem mesclaram-se de tal forma que naturalizaram seus discursos. A voz do jornalista esteve presente por meio do discurso indireto, quando fez um relato expositivo sobre a precariedade da infraestrutura de duas escolas públicas do DF, apresentado de maneira objetiva e acompanhado de fotos. Porém, privilegiou a voz da autoridade por meio do discurso direto, quando citou diretamente três autoridades de dois poderes diferentes, o Legislativo e o Executivo, dando-lhes voz reiteradamente por meio da funcionalização (VAN LEEUWEN, 2008). O jornalista também apresentou outras vozes - por meio das quais deixou implícito, como a do TDCF, do MPDFT e do Corpo de Bombeiros, e do silêncio de algumas vozes, como a do GDF -, que foram citados indiretamente pelas autoridades e pelo jornalista.

Por um lado, a luta para a escola deixar de ser espaço de exclusão social e de funcionar em prédios provisórios foi salientada pela intertextualidade da voz jornalista com as vozes dos diretores das duas escolas. Por meio dessas vozes, ele construiu uma identidade social para si e para o portal Metrópoles de concordância com o discurso da educação ser inclusiva e de apoio à luta em defesa da escola pública, pois a reportagem do portal foi a duas escolas investigar os fatos, e de indignação com o descaso demonstrado pelo GDF, revelando alto comprometimento com a identidade social criada para o governo local. Entretanto, o jornalista não investigou os interesses envolvidos na disputa entre a escola e o GDF. Por outro, o jornalista adere ao discurso hegemônico jornalístico de direita. Sua escolha de não tratar das políticas estatais, do mercado de trabalho, da dinâmica do mercado imobiliário e da produção de moradias legitimou as relações sociais hegemônicas.

Por meio desse silêncio, ele naturalizou discursos sobre a segregação socioespacial da população pobre (violência institucional) e sobre os efeitos das desigualdades sociais na distribuição de renda e dos serviços (violência estrutural), representando a escola pública do DF apenas como espaço de exclusão social, cujas lutas sociais devem continuar sendo ignoradas pelo poder público.

Em suma, a intertextualidade, combinada com as marcas linguísticas e com o contexto imediato, também constrói padrões de experiência, interação social e identidades sociais, ou seja, posições ideológicas. O jornalista distanciou-se das vozes das autoridades citadas diretamente para criar uma identidade social ambígua para ele e para o portal Metrópoles. Apesar de demonstrar alto comprometimento com a 
identidade social criada para o GDF por meio das metáforas que utilizou e da seleção lexical que fez dos relatos dessas autoridades, ele também legitimou relações sociais hegemônicas.

JUNQUEIRA,T.; SILVA, F. Discursive representations in the journalistic media of the democratic school in the Federal District (DF). Alfa, São Paulo, v.62, n.2, p.297-324, 2018.

- ABSTRACT: This work concerns the horizontal and vertical societal accountabilities, as well as representation and intertextuality, in order to analyze discursive representations of the democratic school, including quality of the democracy (DIAMOND; MORLINO, 2005; O'DONNEL, 1998) and the violence (MINAYO, 2006, 2009) that reproduces relations of dominance and exploration (FAIRCLOUGH, 2003). This study demonstrates how meaningmaking potentials broadcasted by the journalistic media can legitimate social hegemonic relations. The linguistic analysis of verbal, non-verbal and multimodal texts found in an article from the portal "Metrópoles" on public schools of the Federal District focused on the lexical selection of verbal texts, multimodal approach and metaphors used based on the Critical Discourse Analysis (CDA) (FAIRCLOUGH, 2001, 2003, 2006) and on the Theory of Multimodal Social Semiotics (TMSS) (KRESS; VAN LEEUWEN, 2001, 2006 [1996]; KRESS, 2010). This research evidenced that the journalist legitimated social hegemonic relations, despite showing a high level of commitment to the social identity created for the Government of the Federal District by means of metaphors and lexical selection used to depict such authorities.

- KEY WORDS: Critical discourse analysis. Discursive representations. Social semiotics and multimodality theory. School violence.

\section{REFERÊNCIAS}

AMADOR, J. G. Relatório da Câmara Legislativa reprova escolas públicas do DF. Metrópoles, Brasília, 24 mar. 2016. Disponível em: <http://www.metropoles.com/ distrito-federal/educacao-df/relatorio-da-camara-legislativa-reprova-escolas-publicasdo-df>. Acesso em: 19 set. 2017.

DIAMOND, L.; MORLINO, L. (Ed.). Assessing the quality of democracy. Baltimore: John Hopkins University Press, 2005.

FAIRCLOUGH, N. Language and globalization. Nova Iorque: Routledge, 2006.

FAIRCLOUGH, N. Analysing discourse: textual analysis for social research. Londres: Routledge, 2003.

FAIRCLOUGH, N. Discurso e mudança social. Brasília: Ed. da UnB, 2001.

FAIRCLOUGH, N. Language and power. Londres: Longman, 1991. 
HALliDAY, M. A. K. An introduction to functional grammar. 2.ed. Londres: Edward Arnold, 1994.

HALLIDAY, M. A. K. Language as social semiotic. Londres: Edward Arnold, 1978. HODGE, R.; KRESS, G. Social semiotics. Cambridge: Polity, 1988.

KRESS, G. Multimodality: a social semiotic approach to contemporary communication. Nova Iorque: Routledge, 2010.

KRESS, G.; VAN LEEUWEN, T. Reading images: the grammar of visual design. 2. ed. Londres: Routledge, 2006 [1996].

KRESS, G.; VAN LEEUWEN, T. Multimodal discourse: the modes and media of contemporary communication. Londres: Edward Arnold; Nova Iorque: Oxford University Press, 2001.

LAGE, N. A reportagem: teoria e técnica de entrevista e pesquisa jornalística. Rio de Janeiro: Record, 2009.

LAKOFF, G.; JOHNSON, M. Metáforas da vida cotidiana. Campinas: Mercado de Letras; São Paulo: Educ, 2002.

MINAYO, M. C. de S. Conceitos, teorias e tipologias de violência: a violência faz mal à saúde. In: NJAINE, K.; ASSIS, S. G.; CONSTANTINO, P. (Org.). Impactos da violência na saúde. Rio de Janeiro: Fiocruz, 2009. p. 21-42.

MINAYO, M. C. de S. Violência e saúde. Rio de Janeiro: Fiocruz, 2006.

MOISÉS, J. A. (Org.). O papel do Congresso Nacional no presidencialismo de coalizão. São Paulo: Núcleo de Pesquisa de Políticas Públicas/USP; Fundação Konrad Adenauer, 2011.

O’DONNELL, G. Accountability horizontal: la institucionalización legal de la desconfianza política. POSTData: Revista de Reflexión y Análisis Político, Buenos Aires, v. 7, p. 11-34, mai. 2001.

O’DONNELL, G. Accountability Horizontal e Novas Poliarquias. Lua Nova: Revista de Cultura e Política, São Paulo, n. 44, p. 27-54, mai./ago. 1998.

PNUD. Relatório do desenvolvimento humano 2015. [ONU, 2015]. Disponível em: <http://hdr.undp.org/sites/default/files/hdr15_overview_pt.pdf>. Acesso em: 28 abr. 2016.

SODRÉ, M.; FERRARI, M. H. Técnica de reportagem: notas sobre a narrativa jornalística. 6. ed. São Paulo: Summus, 1986. (Novas buscas em comunicação, v. 14).

TORRES, H. da G. et al. Pobreza e espaço: padrões de segregação em São Paulo. Estudos Avançados, São Paulo, v.17, n. 47, p. 97-128, jan./abr. 2003. 
VAN LEEUWEN, T. Discourse and practice: new tools for critical discourse analysis. Nova Iorque: Oxford University Press, 2008.

Recebido em 3 de abril de 2017

Aprovado em 15 de setembro de 2017 